\title{
CAPACIDADES ECOEFICIENTES E AS INTERFERÊNCIAS NO DESEMPENHO SOCIAL: UM ESTUDO DAS UNIDADES FEDERATIVAS DO BRASIL
}

\section{Eco-Eficient Capabilities and Interferences in Social Performance: A Study of the Federative Units of Brazil}

\author{
Marcos Chiodini \\ Graduação em Gestão Imobiliária pela Universidade Federal do \\ Paraná. Curitiba, PR. Brasil.e-mail:chiodini.marcos@gmail.com
}

\author{
Janaína Gabrielle Moreira C. da Cunha Amarante \\ Doutoranda em Administração. Pontifícia Universidade Católica - \\ PUC Paraná. Docente de cursos de pós graduação em Administração. \\ Curitiba, PR. Brasil.e-mail:gabrielle88_@hotmail.com
}

\section{RESUMO}

O propósito deste estudo é contribuir com as discussões socioambientais no âmbito da gestão governamental, adentrando na relação entre ecoeficiência e desempenho social. O estudo consistiu em um perfil descritivo, com uma abordagem quantitativa cujo processo ocorreu em dois momentos: para estabelecer os scores de ecoeficiência, foi empregada a técnica não paramétrica FDH com o modelo orientado para insumos e na sequência foi utilizada a correlação linear de Pearson, buscando encontrar possível associação entre os constructos investigados. Os resultados evidenciam que as Unidades Federativas ecoeficientes tendem a ter maior potencial econômico. Sob a análise comparativa regional, o Sul e o Sudeste, em conjunto, apresentam melhores índices de ecoeficiência e baixos índices de ineficiência. As regiões benchmarking, apresentam correlação linear negativa moderada, sugerindo que a desigualdade social tende a diminuir à medida que o score de ecoeficiência aumenta. Espera-se que tais resultados norteiem, quanto ao apelo prático, às políticas públicas no que tange à eficiência econômica e ambiental. Não obstante, são designadas também contribuições teóricas para a comunidade científica quanto ao preenchimento da lacuna de literatura na área em questão, trazendo uma nova compreensão do tema de forma abrangente e descortinando novas possibilidades de pesquisas relacionadas ao alinhamento entre as perspectivas ambientais e sociais e a gestão pública, bem como oportunidades de replicação e exploração mais específicas e particulares de cada Unidade Federativa investigada.

Palavras-chave: Ecoeficiência. FDH. Desempenho Social. Índice de Gini.

\section{ABSTRACT}

The purpose of this study is to contribute to the socio-environmental discussions within the scope of government management, entering into the relationship between eco-efficiency and social performance. The study consisted of a descriptive profile, with a quantitative approach whose process occurred in two moments: to establish the eco-efficiency scores, the non-parametric FDH technique was used with the input-oriented model and in the sequence the linear correlation of Pearson, seeking to find possible association between the investigated constructs. The results show that the eco-efficient Federative Units tend to have greater economic potential. Under the regional comparative analysis, the South and Southeast, together, present better eco-efficiency indices and low levels of inefficiency. The benchmarking regions present moderate negative linear correlation, suggesting that social inequality tends to decrease as the eco-efficiency score increases. It is hoped that such results will guide, as far as the practical appeal, public policies regarding economic and environmental efficiency. Nonetheless, theoretical contributions are also made to the scientific community regarding the filling of the literature gap in the area in question, bringing a new approach to the topic comprehensively and revealing new possibilities for research related to the alignment between the environmental and social perspectives and the public management, as well as more specific replication and exploitation opportunities of each Federative Unit investigated.

Keywords: Eco-efficiency. FDH. Social Performance. Gini index. 


\section{INTRODUÇÃO}

As profundas transformações ocorridas na sociedade, ocasionadas por novos posicionamentos socioambientais e novos estímulos aos debates às questões ambientais, são consequências das preocupações advindas pelo crescimento populacional, consumo e consequentemente à necessidade de atendimento às demandas de um modo geral, sob a ótica da utilização mais eficiente dos recursos naturais (HINTERBERGERET et al., 2000; GUO, LO, TONG; 2016). Promover a ecoeficiência e buscar o desenvolvimento sustentável tornaram-se escolhas inevitáveis (HUANG; LI; YU, 2018).

A definição de ecoeficiência tem sido trabalhada anteriormente aos anos 70, com o progresso do entendimento acerca da eficiência ambiental (FREEMAN et al., 1973), contudo a consolidação e efetiva da conceituação "ecoeficiência" foi marcada no ano de 1990, por meio Schaltegger e Sturm (1990), os quais trouxeram a referida definição e realizaram a conexão do desenvolvimento sustentável aos negócios empresariais, sendo então divulgado e difundido por meio do World Business Council for Sustainable Development (WBCSD) (SCHMIDHEINY, 1992) que defende a promoção da mudança da percepção da indústria em relação às questões ambientais na forma de relação harmônica entre economia e ecologia, visando a sustentabilidade, isto é, produzir mais com menos.

De modo geral, a ação ecoeficiente centraliza-se em ocasiões favoráveis de negócios e possibilita apresentação de um perfil ambientalmente responsável e, concomitantemente, a gestão mais efetiva de seus recursos, com impactos em seus resultados financeiros mais lucrativos, como expõe Bleischwitz (2003), ao mesmo tempo em que incentivam a atitude original e, por consequência, a competitividade e o progresso (WBCSD, 2000b). No contexto da supremacia econômica, caso a eficiência econômica seja agrupada à eficiência ambiental, conduz à ecoeficiência (BLEISCHWITZ, 2003; HUANG; LI; YU, 2018). Nessa esfera, entende-se, portanto, que a ecoeficiência faz parte do movimento sustentável também das instituições públicas (SAVITZ; WEBER, 2007; GOMÉZ et al., 2018).

Além da abordagem ambiental, o desempenho social regional passa a ser parte integrante de in- quietações neste âmbito. Segundo Lenza (2011), o Brasil teve avanço significativo com relação à ordem social nos anos 2000. A Constituição Federal de 1988, diferentemente das antecessoras, não apenas intencionou estruturar o Estado e defender os sujeitos contra os descomedimentos governamentais, mas também concretizou em seu Título VIII uma fração exclusiva à ordem social. Conforme o artigo 193 dessa Constituição, a ordem social fundamenta-se na primazia laboral e tem como propósitos o bem-estar e a integridade social, definindo harmonia ideal com a ordem econômica, que se baseia ainda nos termos do artigo 170, caput, no reconhecimento do trabalho humano e na atitude liberal (LENZA, 2011).

Nesse sentido, Arretche (2018) explica a ocorrência da considerável queda na desigualdade de renda no Brasil nas duas últimas décadas, contrariando o que aconteceu nas décadas de 1960, 1970 e 1980. Nos anos 2000, a renda de metade da população mais pobre aumentou 69\%, enquanto isso aconteceu com 10\% da população mais rica da década de 1960. Portanto, afirma-se que o País está vivendo a época com menor nível de desigualdade desde então.

O tema é tão emergente que a pauta principal de discussões políticas mundiais volta-se ao ponto de conciliar o crescimento econômico sem comprometer ou esgotar os recursos naturais insubstituíveis, preservando as riquezas naturais e os sistemas ecológicos, além de promover a redução das desigualdades sociais (HUANG et al., 2018).

A partir do contexto apresentado, fica evidente a necessidade de estudos que se inclinem para a análise da relação da ecoeficiência e o desempenho social, uma vez que tal abordagem não tem sido considerada sob a perspectiva regional, com reconhecida escassez. Ao mesmo tempo torna-se necessário compreender o panorama econômico, as políticas ambientais e a gestão pública no que concerne à utilização eficiente dos recursos, em especial, no domínio dos impactos sociais. Esta preocupação apresenta-se como atual, com tendências semelhantes e recentes no exterior, como o estudo de Bai et al. (2017), o qual realiza a mensuração da ecoeficiência urbana da China. Tais argumentos direcionam à problemática, a qual se expressa como o norte desta pesquisa: Qual a relação entre a ecoeficiência e o desempenho social das Unidades Federativas do Brasil? 
Dessa maneira, a análise a ser conduzida neste trabalho tem a intenção de promover novas contribuições para o campo científico e seus respectivos debates, consistindo, primeiramente, na identificação da ecoeficiência das Unidades Federativas do Brasil, em termos de indicadores habitacionais, sociambientais e econômicos. Identificá-la torna relevante porque nem sempre o retorno social, considerando o recurso destinado, é proeminente, por vezes seu efeito é nulo ou negativo. E essa alocação de recursos nas regiões brasileiras que não apresentaram o resultado esperado, necessita ser conhecida e estudada pelos gestores públicos. Para regiões que não se apresentaram ecoeficientes, a elaboração de ações estratégicas direcionadas à revisão dos recursos alocados podem ser realizadas, considerando sua estrutura existente, de forma a gerar maiores resultados à sociedade e a melhor condução e gestão dos recursos naturais.

Consequentemente, contribuições destinadas à identificação de correlação da ecoeficiência com o desempenho social também é apresentado neste estudo, viabilizando uma visão particularizada e diferenciada da relação com o índice de Gini, uma vez que se observa a ausência de estudos que direcionem especificamente à abordagem desta pesquisa.

Logo, o objetivo fulcral deste estudo é investigar a relação entre ecoeficiência e o desempenho social das Unidades Federativas do Brasil, proposta esta com perfil inédito no âmbito nacional. Assim, este artigo está dividido em cinco seções: na primeira configura-se na presente introdução; na sequência o referencial teórico é destinado para a definição da ecoeficiência, a Ecoeficiência e desenvolvimento regional, os principais estudos acerca da ecoeficiência na gestão de recursos e o Desempenho Social e o índice de Gini; na terceira, descreve-se a metodologia utilizada no estudo; na quarta, se analisa e se discute os dados; por fim, na quinta seção, são apresentadas as considerações finais e as sugestões para futuras pesquisas.

\section{REFERENCIAL TEÓRICO-EMPÍRICO}

\subsection{Definição de Ecoeficiência}

O conceito de ecoeficiência surgiu com a publicação do livro "Mudança de Rumo", de Stephan Schmidheiny, no ano de 1990. Schmidheiny foi fundador do Business Council for Sustainable Development WBCSD - e lutava por uma evolução da consciência do empresariado com relação às questões ambientais. Este conceito agrega componentes entendidos como fundamentais para o crescimento do êxito econômico, através do uso mais adequado dos recursos e de menos emissões nocivas ao ambiente. Desse modo, em sua originalidade, o conceito significa usar menos do que é preciso pagar, como os recursos, e produzir menos daquilo pelo que se é penalizado ou autuado, como no caso da poluição e, ainda assim, lucrar mais (WBCSD, 2000a)

Martínez Alier (2007) opina que a essa definição é interposta entre o utilitarismo e os prejuízos ambientais que continuam ocorrendo e sendo camuflados pelo crescimento econômico. Nesse sentido, destaca-se que as organizações apossam-se da ecoeficiência para agregar estratégias de marketing às suas ações, entretanto, a comercialização da biodiversidade é um fator de risco à preservação ambiental, por isso, as condutas passam a ser conflitantes.

A expressão é uma junção de eficiência econômica e ecológica, isto é, diminui um impacto ecológico, ao mesmo tempo em que agrega valor econômico (MICKWITZ et al., 2006; HUANG et al., 2014). O WBCSD (2000a) advoga que a ecoeficiência é atingida por meio da oferta de produtos e serviços por preços competitivos, que, por um lado, atenda às demandas humanas e colabore para a qualidade de vida e, por outro, diminua gradativamente o impacto ecológico e a intensidade de uso de recursos no decorrer do ciclo de vida, até alcançar um grau que, ao menos, seja sustentável para o planeta. 
De outro ponto, existe ainda a interrogação sobre quais as características devem ser levadas em conta para a categorização de uma organização como ecoeficiente. A obra de Reyes e Vicente (1998) América Latina en el camino de la ecoeficiencia mostra exemplos de organizações em todo o mundo, as quais são consideradas ecoeficientes pelos Conselhos empresariais de seus respectivos países, mas há dados que a obra não apresenta. Em nenhum momento, por exemplo, aponta a transferência de emissões, que muitas vezes é a razão da industrialização de países latinos e mostra as ameaças do esgotamento de energia para esses países. Para Beck (2010), a "miopia econômica" faz com que os atingidos satisfaçam-se com o progresso econômico ao mesmo tempo que aumentam os prejuízos ambientais em longo prazo.

Li et al. (2017) asseveram que a ecoeficiência mensura a capacidade de maximização da criação de bens e serviços, e, em paralelo, a minimização do uso de recursos e degradações ambientais. Logo, a abordagem acerca da ecoeficiência é considerada como multidisciplinar (GOMÉZ et al., 2018) e não pode se apresentar apenas sob uma perspectiva macro de empresas ou instituições, mas aplicável a cenários regionais e governamentais, cujo contexto é apresentado e discutido na seção seguinte.

\subsubsection{Ecoeficiência e desenvolvimento regional}

$\mathrm{O}$ entendimento predominante admite que as declarações que introduziam a ecoficiência, de maneira restritiva, apenas às empresas e indústrias, já foram superadas, trazendo novas oportunidades e perspectivas de análise, como cidades, países e regiões (BAI et al., 2018; LI et al., 2017), expandindo assim a articulação econômica e ambiental a um sentido ainda mais amplo.

Neste sentido, é importante trazer a visão de Silva (1998), ao alegar que o meio ambiente, sendo parte da ordem social, é a integração do agrupamento de partículas naturais, artificiais e culturais que possibilitem o desenvolvimento justo da vida em todas as suas possibilidades. $\mathrm{O}$ autor coloca que, objetivando a defesa desse elemento da esfera social, o artigo $225 \mathrm{da}$ Constituição vigente esclarece que o meio ambiente ecologicamente equiparado é direito de todos, bem de uso geral do povo e fundamental à boa qualidade de vida, exigindo-se do Poder Público e dos cidadãos a obrigação de protegê-lo e preservá-lo para as atuais e futuras gerações. Sendo assim, fica evidente que qualquer papel exercido pela administração pública, bem como toda atuação da coletividade, tem que considerar a preservação do meio ambiente.

Almeida (2002) assevera que é a administração do desenvolvimento pontual ou inclusivo, nos governos e demais organizações, que deve levar em conta as conjunturas ambientais, econômicas e sociais visarem à garantia de permanência da base natural, da infraestrutura econômica e social. O estudo de Alcântara, Pereira e Silva (2015) revela a preocupação da comunidade científica acerca de discussões mais resolutas e necessárias contribuições teóricas a respeito da gestão social e governança pública no âmbito nacional.

Para Borges, Monteiro e Nogueira (2006), conforme a Comissão Mundial sobre o Meio Ambiente e Desenvolvimento (CMDMA), o desenvolvimento sustentável fundamenta-se no tripé: equilíbrio ambiental, equidade social e crescimento econômico. Em meados da década de 1990, esse tripé da sustentabilidade estimulou o estudioso inglês John Elkington a criar a expressão triple bottom line, isto é, o desenvolvimento sustentável não pode deixar de lado os fatores ambientais, econômicos e sociais.

De forma complementar, Boos (2007), expõe que o Desenvolvimento Regional Sustentável é uma estratégia de negócios que considera argumentos como implantar ações objetivando o desenvolvimento sustentável e a inclusão social no plano organizacional, proposições associadas ao compromisso socioambiental, e agir em conformidade com ações e 
políticas de governo. Normalmente, colaboram como agentes a organização financeira, setores associados à atividade exercida (como as associações de classe) e a comunidade em que o plano será implantado.

O governo nacional incluiu a Agenda $21 \mathrm{Bra}-$ sileira em seu Plano Plurianual (PPA 2004-2007), cujo programa visa à promoção da internalização dos preceitos e estratégias da Agenda 21 Brasileira na elaboração e implantação de políticas públicas nacionais e regionais, através do planejamento estratégico descentralizado e colaborativo, o qual define as prioridades a serem delimitadas e colocadas em prática por meio de parceria governo-sociedade, do ponto de vista do desenvolvimento sustentável (BOSS, 2007).

A partir das novas configurações e demandas acerca da responsabilidade socioambiental, passou a ficar evidente que a ecoeficiência está totalmente relacionada à harmonia entre o desenvolvimento humano e a proteção ambiental, e, consequentemente, entre a ecologia natural e ecologia humana. A ecoficiência pode ser considerada uma ferramenta eficaz para medir o sistema composto pela "natureza-economia-sociedade" assegurando, sobretudo, o desenvolvimento sustentável. (Li et al., 2017).

O Desenvolvimento Regional Sustentável procura proporcionar o desenvolvimento local através do suporte a ações produtivas que sejam economicamente viáveis, corretas ambiental e socialmente, sempre notando e respeitando a diversidade cultural das comunidades em que é implementado (BOOS, 2007). De acordo com Li et al. (2017), a melhoria da ecoeficiência torna-se um importante ponto de avanço para promover a coordenação entre o desenvolvimento econômico e o meio ambiente de uma região, na gestão efetiva de recursos.

\subsubsection{Principais estudos acerca da ecoeficiência na gestão de recursos}

Pesquisas desenvolvidas acerca da ecoeficiência na gestão de recursos vêm se constituindo como importantes motores propulsores para o desenvolvimento de novos estudos. Nesta esfera, são apresentados os principias estudos nacionais e internacionais que abarcam esta temática e forneceram subsídios para o desenvolvimento da presente pesquisa.

$\mathrm{Na}$ configuração desta abordagem, a procura contínua por resoluções que reduzam os entraves ambientais faz com que administradores usem mecanismos que ajudem as organizações em todo o mundo a atuar de modo proativo referente às questões associadas à administração de recursos naturais (VAN BERKEL, 2006). Sendo assim, conforme Barbieri (2004), foram elaborados padrões conceituais e métodos específicos para diminuir a poluição e elevar a sustentabilidade ambiental nas ações organizacionais, como a Produção Mais Limpa (PML) e a Gestão Ambiental.

Com o objetivo de diferenciar a ação estatal da ação dos demais agentes sociais, Pereira, Santa e Andrade (2012) chegaram à conclusão de que a definição de ecoeficiência não integra o contexto do governo, uma vez que aquela segue os fundamentos do lucro, o que se difere do interesse do Estado. Logo, a ação do governo de defesa ao ambiente precisa ser irrestrita e potencializada, impondo limites quando a definição de ecoeficiência menosprezar a defesa ambiental por conta do lucro.

Por outra esfera, em análise sobre indicadores e metodologias de mensuração referentes à ecoeficiência, Munck, Oliveira e Bansi (2011) observaram que os indicadores pesquisados - do WBCSD e do Global Reporting Initiative (GRI) -, frente aos padrões de análises usados, não apresentam credibilidade suficiente para ratificar que mensuram a ecoeficiência de modo eficaz. Porém, são úteis como subsídios para formulação de indicadores adequados à conjuntura de cada organização.

Segundo Van Berkel (2006), o propósito da Produção Mais Limpa é fundamentalmente básico e objetivo: reduzir desperdícios e emissões pela supressão de suas causas já na formulação de produtos e serviços, em vez de tratá-los depois de inventados. Assim, as circunstâncias favoráveis aos negócios, consequentes da diminuição no investimento das tecnologias associadas ao ambiente, geraram um quadro favorável às organizações, aumentando a rentabilidade com racionalização de processos e consideração ambiental. 
Considerando isso, Jabbour et al. (2008) elucida que as discussões de temáticas do meio ambiente na esfera das organizações já se apresenta como demanda efetiva, porém os rodeios associados à produção científica desse setor ainda são pouco estudados. Conforme Van Berkel (2006), as expressões "Produção Mais Limpa" e "Ecoeficiência" não têm sido admitidas de forma estratégica como poderiam, sendo constantemente entendidas como tecnologias ambientais.

Em um estudo de Jabbour (2010) com 94 empresas brasileiras que apresentam a certificação ISO 14001, verificou-se que o progresso da gestão ambiental organizacional tem tendência a acontecer em duas etapas evolutivas: a sinergia para a ecoeficiência e a visão da legislação ambiental. A pesquisa propõe também que o progresso da gestão ambiental nas organizações tem tendência a acontecer de modo não linear.

O período após a Conferência das Nações Unidas sobre ambiente e desenvolvimento que aconteceu no Rio em 1992 mostrou uma ampla experimentação e efetivação dos termos Produção Mais Limpa e Ecoeficiência. Isso engloba ainda as estratégias adicionais para utilização correta e eficaz de materiais, energia, água e outros recursos naturais nos negócios (VAN BERKEL, 2006).

Em estudo conjunto, Del Rio et al. (2011) mostram alguns números que comprovam que somente os investimentos em tecnologias end-of-pipe (ou fim de tudo) são contabilizados por conta dos entraves sistêmicos de se fragmentar medidas de Produção Mais Limpa dos investimentos em tecnologias não ambientais.

Já em outro contexto, Oggionia et al. (2011) concluem que, para se de medir a Ecoeficiência em uma vasta proporção mundial, há um problema de dados, uma vez que as políticas ambientais não são fortemente admitidas em todo o mundo.

Frente às poucas pesquisas sobre Ecoeficiência, alguns segmentos começam a reconhecer a relevância dessa atitude na organização, como também a relevância econômica, ação ambiental e social. Para Franklin e Spinler (2011), essa definição é fundamental e proativa ao posicionamento estratégico, mostrando um modelo no transporte de mercadorias, que lamentavelmente ainda é um dos colaboradores primordiais para o aquecimento global, congestionamentos, entraves associados à segurança e poluição dos municípios.

Em outro trabalho, Van Berkel (2006) mostra o desenvolvimento e implantação da Produção Mais Limpa e Ecoeficiência na região Oeste australiana, quando aponta a relevância das quatro fases de implantação: pesquisa, experimentação, implementação e reorientação; ressaltando a importância de políticas públicas e a construção de vínculos intersetoriais na implantação da Produção Mais Limpa e Ecoeficiência. Nessa esfera, o autor elucida que as definições de Ecoeficiência e Produção Mais Limpa são complementares, em que a primeira está direcionada ao contexto estratégico (criação de valor) e a segunda foca-se no contexto operacional (produtivo).

Já em estudo mais recente, Amarante e Tortato (2016) buscaram pesquisar a colaboração do que foi produzido sobre ecoeficiência e quais as técnicas de mensuração são mais usadas. A pesquisa examinou a produção internacional na área da Administração, através do método de revisão sistemática, com o levantamento de periódicos recentes com fator de impacto significativo, sendo estudados 43 trabalhos. Como resultado, verificaram e classificaram-se nove eixos temáticos e mapeadas as colaborações teóricas e metodológicas da área.

Os recentes estudos de Gómez et al. (2018), Huang, Li e Yu (2018) e Bai et al., (2017) denotam um novo rumo de pesquisas científicas relacionadas à temática ecoeficiência, não apenas para análise produtiva empresarial mas para a investigação do equilíbrio entre a urbanização e o ambiente ecológico, a partir da minimização das compensações e maximização das sinergias para desenvolvimento regional, considerando aspectos como consumo populacional dos recursos naturais, a expansão das cidades, ocupação de terras e a respectiva poluição ambiental.

Ainda que reduzidos, os estudos no âmbito da ecoeficiência que discutem e analisam a gestão de recursos formam um campo amplo para o desenvolvimento de futuras pesquisas. O Quadro 1, abaixo, realiza uma síntese dos principais estudos que contemplam esta abordagem: 
Quadro 1 Principais estudos acerca da ecoeficiência na gestão de recursos

\begin{tabular}{|c|c|c|c|c|}
\hline $\begin{array}{l}\text { Autor/ } \\
\text { Ano }\end{array}$ & Título & $\begin{array}{l}\text { Objeto de investi- } \\
\text { gação }\end{array}$ & Teste realizado & Resultados da pesquisa \\
\hline 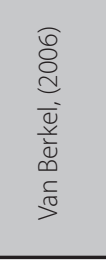 & $\begin{array}{l}\text { Cleaner production } \\
\text { and eco-efficiency }\end{array}$ & $\begin{array}{l}\text { Produção Mais Limpa } \\
\text { e Ecoefciência na } \\
\text { Austrália }\end{array}$ & $\begin{array}{l}\text { Quatro fases de implantação: pes- } \\
\text { quisa, experimentação, implementa- } \\
\text { ção e reorientação }\end{array}$ & $\begin{array}{l}\text { As definições de Ecoeficiência e } \\
\text { Produção Mais Limpa são comple- } \\
\text { mentares, em que a primeira está } \\
\text { direcionada ao contexto estratégico } \\
\text { (criação de valor) e a segunda } \\
\text { foca-se no contexto operacional } \\
\text { (produtivo). }\end{array}$ \\
\hline 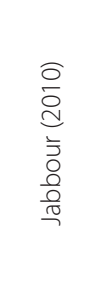 & $\begin{array}{l}\text { Non-linear path } \\
\text { ways of corporate } \\
\text { environmental } \\
\text { management: a survey } \\
\text { of ISO } 14001 \text {-certified } \\
\text { companies in Brazil }\end{array}$ & $\begin{array}{l}94 \text { empresas brasileiras } \\
\text { que apresentam a } \\
\text { certificação ISO } 14001\end{array}$ & $\begin{array}{l}\text { A evolução da gestão ambiental } \\
\text { corporativa foi avaliada de forma sis- } \\
\text { temática e integrada em um quadro } \\
\text { teórico típico contendo três estágios } \\
\text { evolutivos: reativos, preventivos e } \\
\text { proativos. }\end{array}$ & $\begin{array}{l}\text { O progresso da gestão ambiental } \\
\text { organizacional tem tendência a } \\
\text { acontecer em duas etapas evoluti- } \\
\text { vas: a sinergia para a ecoeficiência } \\
\text { e a visão da legislação ambiental. } \\
\text { O progresso da gestão ambiental } \\
\text { nas organizações tem tendência a } \\
\text { acontecer de modo não linear. }\end{array}$ \\
\hline 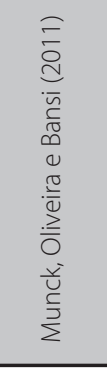 & $\begin{array}{l}\text { Ecoeficiência: uma } \\
\text { análise das metodo- } \\
\text { logias de mensuração } \\
\text { e seus respectivos } \\
\text { indicadores }\end{array}$ & $\begin{array}{l}\text { Indicadores e metodo- } \\
\text { logias de mensuração } \\
\text { referentes à ecoefici- } \\
\text { ência }\end{array}$ & $\begin{array}{l}\text { Analisaram as possíveis fragilida- } \\
\text { des dos indicadores utilizando-se } \\
\text { como parâmetro os Princípios de } \\
\text { Bellagio, que sintetizam a percepção } \\
\text { geral sobre os principais aspectos } \\
\text { relacionados aos indicadores da } \\
\text { sustentabilidade. }\end{array}$ & $\begin{array}{l}\text { Observaram que os indicadores pes- } \\
\text { quisados - do WBCSD e do Global } \\
\text { Reporting Initiative (GRI) -, frente } \\
\text { aos padrões de análises usados, não } \\
\text { apresentam credibilidade suficiente } \\
\text { para ratificar que mensuram a } \\
\text { ecoeficiência de modo eficaz. Porém, } \\
\text { são úteis como subsídios para for- } \\
\text { mulação de indicadores adequados } \\
\text { à conjuntura de cada organização. }\end{array}$ \\
\hline 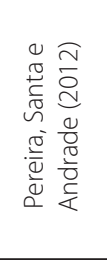 & $\begin{array}{l}\text { O conceito de ecoefi- } \\
\text { ciência e o papel das } \\
\text { políticas públicas na } \\
\text { efetivação da gestão } \\
\text { ambiental. }\end{array}$ & $\begin{array}{l}\text { Ação estatal e ação } \\
\text { dos demais atores } \\
\text { sociais }\end{array}$ & $\begin{array}{l}\text { A partir de levantamento bibliográfi- } \\
\text { co, fez-se análise de conceitos como } \\
\text { políticas públicas e ecoeficiência, } \\
\text { para posterior verificação de como } \\
\text { esses elementos se mostram na } \\
\text { gestão ambiental de determinado } \\
\text { local. }\end{array}$ & $\begin{array}{l}\text { Chegaram à conclusão de que a de- } \\
\text { finição de ecoeficiência não integra } \\
\text { o contexto do governo, uma vez } \\
\text { que aquela segue os fundamentos } \\
\text { do lucro, o que se difere do interesse } \\
\text { do Estado. }\end{array}$ \\
\hline 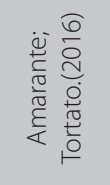 & $\begin{array}{l}\text { Proeminências da } \\
\text { ecoeficiência: uma } \\
\text { revisão sistemática das } \\
\text { produções internacio- } \\
\text { nais de alto impacto }\end{array}$ & $\begin{array}{l}\text { Produção interna- } \\
\text { cional na área da } \\
\text { Administração }\end{array}$ & $\begin{array}{l}\text { Método de revisão sistemática, } \\
\text { com o levantamento de periódicos } \\
\text { recentes com fator de impacto } \\
\text { significativo, sendo estudados } 43 \\
\text { trabalhos. }\end{array}$ & $\begin{array}{l}\text { Verificaram e classificaram-se nove } \\
\text { eixos temáticos e mapeadas as } \\
\text { colaborações teóricas e metodológi- } \\
\text { cas da área. }\end{array}$ \\
\hline 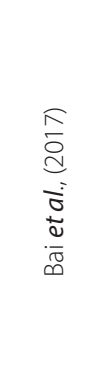 & $\begin{array}{l}\text { Exploring the } \\
\text { relationship between } \\
\text { urbanization and } \\
\text { urban eco-efficien- } \\
\text { cy: Evidence from } \\
\text { prefecture-level cities } \\
\text { in China }\end{array}$ & $\begin{array}{l}\text { É mensurada a ecoefi- } \\
\text { ciência urbana de } 281 \\
\text { cidades na China. } \\
\text { durante } 2006 \text { e } 2013 \\
\text { e explorada a urbani- } \\
\text { zação e ecoeficiência } \\
\text { urbana }\end{array}$ & $\begin{array}{l}\text { DEA (Análise por envoltória de da- } \\
\text { dos) e Análise econométrica espacial }\end{array}$ & $\begin{array}{l}\text { Existe relação entre urbanização } \\
\text { e ecoeficiência urbana, indicando } \\
\text { que com a melhoria da urbanização, } \\
\text { a ecoeficiência urbana primeiro } \\
\text { aumenta, } \\
\text { então declina e depois aumenta } \\
\text { novamente. A melhoria do nível de } \\
\text { tecnologia e da formulação } \\
\text { de políticas ambientais efetivas } \\
\text { promove o aumento da ecoeficiên- } \\
\text { cia urbana. }\end{array}$ \\
\hline
\end{tabular}

Fonte: Dados da pesquisa (2018) 


\begin{tabular}{|c|c|c|c|c|}
\hline $\begin{array}{l}\text { Autor/ } \\
\text { Ano }\end{array}$ & Título & $\begin{array}{l}\text { Objeto de investi- } \\
\text { gação }\end{array}$ & Teste realizado & Resultados da pesquisa \\
\hline 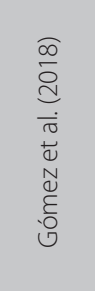 & $\begin{array}{l}\text { Measuring the eco-ef- } \\
\text { ficiency of wastewater } \\
\text { treatment plants un- } \\
\text { der data uncertainty }\end{array}$ & $\begin{array}{l}\text { Avaliação da ecoefici- } \\
\text { ência nas estações de } \\
\text { tratamento de águas } \\
\text { residuais } \\
\text { (ETARs) }\end{array}$ & $\begin{array}{l}\text { Modelo de tolerância ao DEA - Análi- } \\
\text { se por envoltória de dados para } 729 \\
\text { cenários }\end{array}$ & $\begin{array}{l}\text { Estudo pioneiro na avaliação da } \\
\text { eco-eficiência das ETARs. Demons- } \\
\text { tram a importância da integração da } \\
\text { incerteza dos dados de } \\
\text { avaliações da ecoeficiência. Os } \\
\text { desempenhos das ETAR mudam no- } \\
\text { tavelmente com base no conjunto } \\
\text { de cenários avaliados. }\end{array}$ \\
\hline 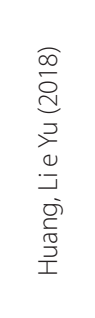 & $\begin{array}{l}\text { Does urban cluster } \\
\text { promote the increase } \\
\text { of urban eco-efficien- } \\
\text { cy? Evidence from } \\
\text { Chinese cities }\end{array}$ & $\begin{array}{l}\text { Mensuração da eco- } \\
\text { eficiência urbana da } \\
\text { China entre os anos de } \\
2003 \text { a } 2015 \text {. } \\
\text { Analisa também os } \\
\text { impactos e mecanis- } \\
\text { mos do aglomerado } \\
\text { urbano na ecoeficiên- } \\
\text { cia urbana. }\end{array}$ & $\begin{array}{l}\text { DEA - Análise por envoltória de } \\
\text { dados }\end{array}$ & $\begin{array}{l}\text { A melhoria do aglomerado urbano é } \\
\text { propícia para melhorar a ecoeficiên- } \\
\text { cia urbana. O aglomerado urbano } \\
\text { beneficia a ecoeficiência urbana } \\
\text { através do efeito de descentraliza- } \\
\text { ção e efeito de otimização estrutural. }\end{array}$ \\
\hline
\end{tabular}

Fonte: Dados da pesquisa (2018)

Na configuração desta abordagem, constata-se a evolução de discussões relacionadas à ecoeficiência na comunidade científica quanto às ameaças, riscos e as incertezas dos impactos ecológicos promovidos pelo crescente consumo de recursos naturais, buscando conduzir a sua respectiva redução, além da preocupação com o crescimento demográfico acelerado e respectivas questões diretivas ao desempenho social.

\subsection{Desempenho Social e o Índice de Gini}

Os desafios do desenvolvimento humano e o progresso econômico de uma região atrelado ao desenvolvimento sustentável, foi pauta da reunião da Cúpula da Organizações das Nações Unidas - ONU, na qual foram lançados os Objetivos do Desenvolvimento Sustentável (ODS), reconhecendo a necessidade de considerar as dimensões social, econômica e ambiental de maneira equilibrada e integrada. Os (ODS), vêm dar continuidade aos compromissos cunhados pelos 8 Objetivos do Milênio (ODM), lançados no ano 2000 com vistas a 2015, que, embora não alcançados em sua plenitude, aceleraram o combate a problemas prioritários na agenda de desenvolvimento humano. Tais constatações direcionam às preocupações globais em torno de uma agenda prioritária: $\mathrm{O}$ desenvolvimento humano, sem comprometimento dos recursos naturais e das gerações futuras (PNUD, 2015).

Neste aspecto, as inquietações universais acerca do tema, são multiplicadas a todas esferas regionais, acerca da compreensão efetiva em lidar com os desafios socioambientais. Logo, a sustentabilidade social refere-se à conquista da equidade e contribuição de todos os conjuntos sociais na formação e conservação do equilíbrio do sistema, dividindo privilégios e obrigações. Para as organizações, o contexto social significa o seu impacto nas estruturas sociais em que trabalham; o desempenho social é, portanto, discutido através dessa análise sobre as partes envolvidas em nível regional, nacional e universal (LORENZETTI, CRUZ e RICIOLI, 2008).

Várias organizações que até então levavam em conta somente os indicadores financeiros para observar os efeitos de suas operações passaram a elaborar ações focadas na sustentabilidade e na ecoeficiência, mas da mesma forma que o olhar econômico, a ecoeficiência também deve ser medida, por isso o uso de indicadores, que são dados proveitosos para a tomada de decisões, os quais traduzem informações e medidas acerca de um fenômeno específico, ajudando no reconhecimento de hiatos entre os propósitos, estratégias e projetos organizacionais (KRAJNC; GLAVIC, 2003). 
De acordo com Mirzaei et al. (2017), o Coeficiente de Gini foi inventado pelo matemático italiano Conrado Gini e geralmente é usado para medir o nível de concentração e/ou distribuição de renda em um grupo específico, indicando a divergência entre os rendimentos dos mais pobres e dos mais afortunados.

Em números, o Coeficiente de Gini oscila de zero a um, porém, ele pode ser apresentado também em pontos percentuais (de zero a cem), quando será denominado Índice de Gini. O número zero significa a condição de equidade, isto é, todos possuem rendas iguais. Já o número um (ou cem) é o oposto máximo, ou seja, somente um indivíduo possui toda a riqueza. Na prática, o Coeficiente ou Índice de Gini compara habitualmente os $20 \%$ mais pobres com os $20 \%$ mais afortunados (MIRZAEI et al.,2017).

O Índice de Gini pode ser calculado a partir da área criada pela curva de Lorenz e a linha de equidade plena (ULTSCH; LÖTSCH, 2017). A curva de Lorenz é delimitada a partir do percentual da população agrupado e de sua contribuição equivalente na renda associada. Assim, é possível visualizar a representação gráfica do Coeficiente de Gini (Figura 1). O eixo horizontal significa a porcentagem de indivíduos e o eixo vertical, a porcentagem da renda. A diagonal significa a equidade ideal de renda e o Coeficiente de Gini é o resultado da operação: a / (a+b) (ROSSETI, 2007).

Figura 1 Representação gráfica do Coeficiente de Gini

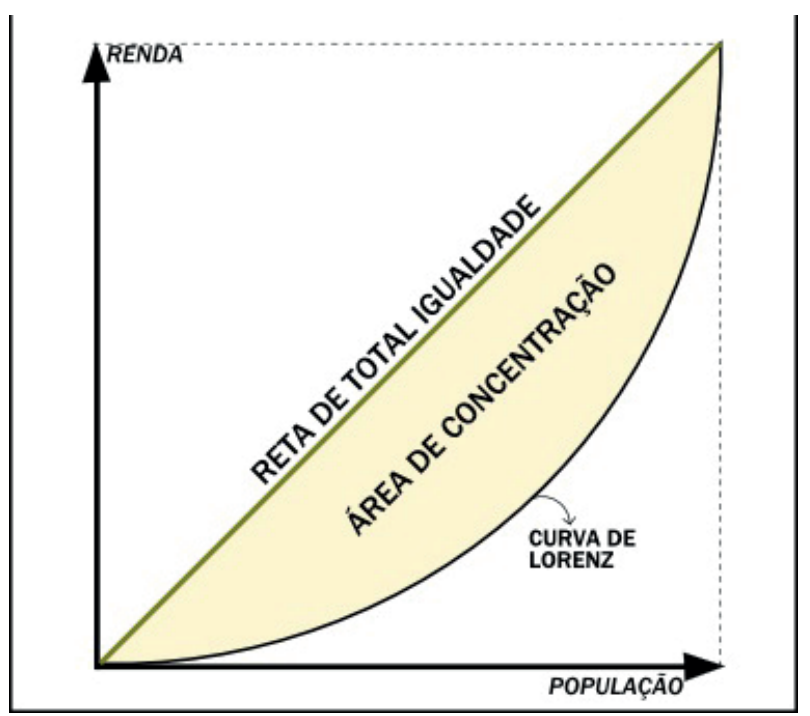

Fonte: Pena (2017)
Jannuzzi (2001) pondera que uma sociedade com conhecimento sobre a região em que vive apresenta mais possibilidade de tomar decisões que influenciem de modo construtivo na qualidade de vida de todos os moradores locais, e os indicadores sociais são um relevante marco para tal. Para o autor, é certo que o saber do significado, das restrições e das potencialidades dos indicadores sociais pode ser muito auspicioso para os sujeitos interessados em estabelecer prioridades sociais, bem como na destinação de recursos do orçamento público. A correta utilização dos indicadores sociais pode enriquecer a análise prática da realidade social e guiar de modo mais competente a avaliação, a elaboração e a implantação de políticas sociais.

\section{MATERIAIS E MÉTODOS}

Com o propósito de contribuir com o desenvolvimento da temática, optou-se pela utilização de um modelo de pesquisa com enfoque descritivo, visando o levantamento de elementos constitutivos para objeto de pesquisa. É possível afirmar que a maneira como foi conduzido, configura-se com abordagem quantitativa, de paradigma epistemológico positivista. A partir de um horizonte temporal longitudinal, a presente análise compreende os anos de 2005 a 2014.

A amostra do estudo foi composta por 26 unidades federativas, sendo que o estado do Amapá foi excluído em função da ausência de dados. A coleta de dados originou-se de fontes secundárias dos estados brasileiros, por meio da pesquisa em plataformas do Sistema Nacional de Informações sobre Saneamento (SNIS), cujos detalhes podem ser observados no Quadro 2. 
Quadro 2 Variáveis de ecoeficiência e desempenho social

\begin{tabular}{l|l|l}
\hline \multicolumn{1}{c|}{ Variável } & \multicolumn{1}{c|}{ Descrição } & Fonte \\
\hline Geração de resíduos & Geração de resíduos sólidos em toneladas ao ano & SNIS \\
\hline Emissão de CO2 & Emissão de gás carbônico em toneladas ao ano & SNIS \\
\hline PIB & Produto Interno Bruto & SNIS \\
\hline Abastecimento de água & Abastecimento de água por habitante & SNIS \\
\hline Coleta de esgoto & Coleta de esgoto por habitante & SNIS \\
\hline Índice de Gini & Mede o nível de concentração e/ou distribuição de renda em um grupo específico & SNIS \\
\hline
\end{tabular}

Fonte: Elaborado pelos autores (2017)

Ressalta-se que todas as variáveis foram coletadas em formato de unidades distintas, visto suas diferentes características. Dessa forma o estudo foi conduzido em duas etapas: Primeiramente foi empregado o teste não paramétrico Free Disposability Hull (FDH), ou Análise Envoltória por Livre Descarte, adequado para análise do modelo em questão. Portanto, no andamento de coleta e avaliação dos dados, foi utilizada a abordagem FDH orientado para insumos, considerando sua flexibilidade e por ser satisfatória para alcançar resultados de modelagem, sendo oportuno utilizá-lo com o limite guiado para o material necessário e com efeitos contínuos de escala, pois se objetiva verificar a ecoeficiência das Unidades Federativas do Brasil, para posterior análise da relação com o desempenho social. A partir do levantamento de dados, foram classificados dentro do modelo, as métricas de entradas e saídas, consistindo: (i) inputs: consumo de energia elétrica nos sistemas de água e de esgoto, volume de água produzido, geração de resíduos sólidos, emissão de CO2; (ii)outputs:PIB, abastecimento de água por habitante, volume de água consumido, coleta de esgoto doméstico e volume de esgoto coletado.

A técnica FDH permite descartar livremente as entradas e saídas, as quais determinam possibilidades do agrupamento produtivo. Considerando isso, cada unidade federativa observada é uma Decision $\mathrm{Ma}$ king Unit (DMU) ou Unidade Tomadora de Decisão. Daraio e Simar (2007) afirmam que técnicas como a $\mathrm{FDH}$, que permitem a livre descartabilidade, com tecnologia produtiva não paramétrica para análise de ecoeficiência, amenizam a hipótese de expansão, pois ficam restritivas nas pesquisas. Para a estimativa do teste $\mathrm{FDH}$, foi usado como suporte o pacote estatístico STATA $^{\oplus} 13$. Assim, a análise da ecoeficiência orientada para insumos da DMU é estimada pela Equação 1, conforme orientam Daraio e Simar (2007):

$\hat{\theta}_{F D H}\left(x_{0}, y_{0}\right)=\min _{i \in D 0}\left(\frac{X_{i}}{x_{0}}\right)$

Debreu (1951) orienta que, na avaliação dos scores, leva-se em conta que o coeficiente de eficiência precisa ser avaliado entre os parâmetros 0 e 1 , em que, para adaptação deste estudo, o 0 refere-se à ecoeficiência nula e 1 à ecoeficiência completa.

A segunda etapa consistiu no emprego da técnica de correlação de Pearson, para identificar o coeficiente de correlação linear entre a ecoeficiência e o desempenho social dos estados brasileiros, como se pode constatar na Equação 2, a seguir:

$r=\frac{\sum\left(x_{i}-\bar{X}\right)\left(y_{i}-\bar{y}\right)}{\left(\sum\left(x_{i}-\bar{X}\right)^{2}\right)\left(\sum\left(y_{i}-\underline{\bar{y}}\right)^{2}\right)}$

Em que:

$r=$ coeficiente de correlação de Pearson

$n=$ número de observações da amostra

$x_{i}=$ valor da observação $\mathrm{x}$

$\overline{\mathrm{X}}=$ média da observação $\mathrm{x}$

$y_{i}=$ valor da observação y

$\bar{y}=$ média da observação y 


\section{ANÁLISE DOS RESULTADOS}

O presente estudo foi realizado a partir do emprego de métodos estatísticos quantitativos, com um total de 260 observações. Inicialmente, a fim de verificar as características associadas às variáveis que analisaram a ecoeficiência, bem como o desempenho social em 26 unidades federativas (o estado do Amapá foi retirado do estudo, em função da ausência de dados), foram selecionadas suas estatísticas descritivas. Os resultados são apresentados na Tabela 1, a seguir:

Tabela 1 Estatística Descritiva

\begin{tabular}{l|c|c|c|c|c}
\multicolumn{1}{c|}{ Variável } & Obs. & Média & Desvio Pad. & Min. & Máx. \\
\hline Geração de resíduos & 260 & 2021404 & 3124737 & 345 & $1.97 \mathrm{e}+07$ \\
\hline Emissão de CO2 & 260 & $6.41 \mathrm{e}+07$ & $7.41 \mathrm{e}+07$ & 5003679 & $5.39 \mathrm{e}+08$ \\
\hline PIB & 260 & $1.36 \mathrm{e}+08$ & $2.39 \mathrm{e}+08$ & 3179287 & $1.63 \mathrm{e}+09$ \\
\hline Abastecimento de água & 260 & 6718127 & 8174414 & 290639 & $4.32 \mathrm{e}+07$ \\
\hline Coleta de esgoto & 260 & 5081658 & 7926129 & 242179 & $4.32 \mathrm{e}+07$ \\
\hline Índice de Gini & 260 & .4753889 & .1629344 & 0 & .627 \\
\hline
\end{tabular}

Fonte: Dados da pesquisa (2017).

A partir estatísticas descritivas dispostas na Tabela 1, observa-se que os resultados variam por conta das regiões brasileiras e a divergência de tamanhos entre os estados. Com relação à geração de resíduos, a média nacional é de aproximadamente 2.021.404 toneladas ao ano por estado, sendo que o valor mínimo é de 345 toneladas, no estado do Acre, e o valor máximo é 19.715.898,4, do estado de São Paulo. No período analisado, o Mato Grosso foi o estado que mais emitiu CO2, com 538.890.551 toneladas no ano de 2005 , enquanto a média brasileira ficou em 6.41e+07. Sugere, aqui, que o alto índice de emissão de CO2 atribui-se ao desmatamento da região da Amazônia. No contexto econômico, a média do Produto Interno Bruto (PIB) entre 2005 e 2014 foi 1.36e+08. Roraima apresentou o menor PIB (3.179.287, em 2005), enquanto São Paulo - um dos polos econômicos mais importantes da América Latina, que no mesmo ano de referência já apresentava mais que o dobro do valor de Roraima no PIB, em 2014, mostrou o valor de $1.63 \mathrm{e}+09$, o maior dentre os analisados. Nesse sentido, destaca-se que a média nacional do PIB dos estados ficou em $1.36 \mathrm{e}+08$. A média da população por estado atendida com abastecimento de água de 2005 a 2014 foi de 6.718.127 habitantes, sendo que o Acre foi o estado com menor abastecimento (290.639, em 2007), seguido do estado de Roraima (391.317); já o estado mais privilegiado com água foi São Paulo, com 43.220.749 favorecidos em 2014. Com relação à coleta de esgoto, a população de São Paulo também foi a mais beneficiada, sendo que, apenas em 2014, 43.214.909 habitantes foram atendidas, ao passo que em Roraima, em 2005, somente 242.179 receberam a coleta. A média nacional desse dado no período ficou em 5.081.658. Por último, foi verificado o Índice de Gini dos estados brasileiros. Deste, a média nacional por estado foi de aproximadamente $47 \%$, sendo que o estado com maior índice foi Alagoas, com quase 63\%.

O primeiro teste da presente análise, que tem como objetivo identificar a ecoeficiência das Unidades Federativas do Brasil, foi realizado a partir da eficiência técnica direcionada para outputs, cujo foco consiste no fato de manter as entradas e maximizar as saídas, de modo a chegar aos números que apontem ou não a ecoeficiência dos estados investigados. A Figura 2 apresenta os resultados por meio de gráficos. 
Figura 2 Gráficos de score de ecoeficiência dos estados brasileiros
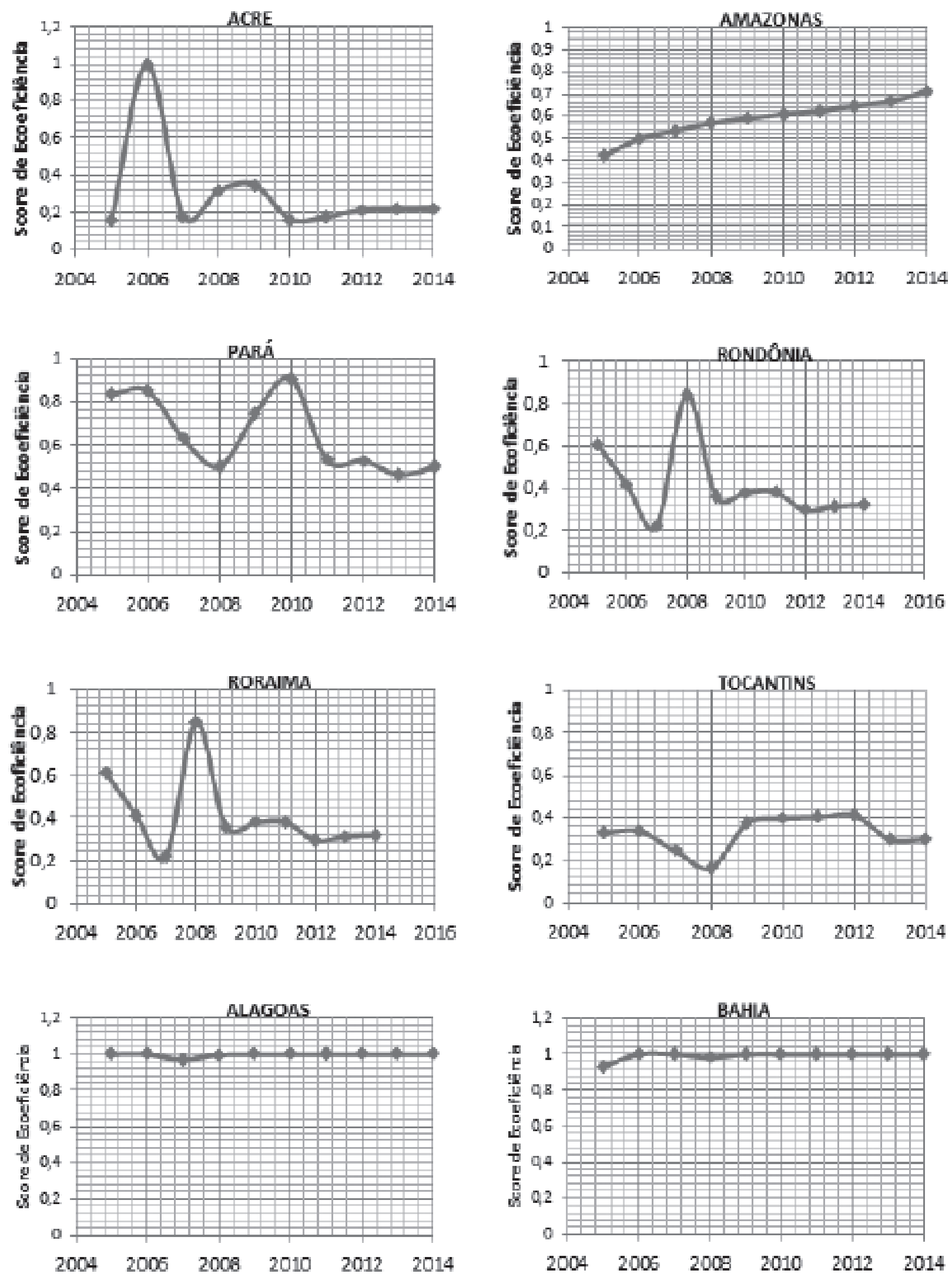

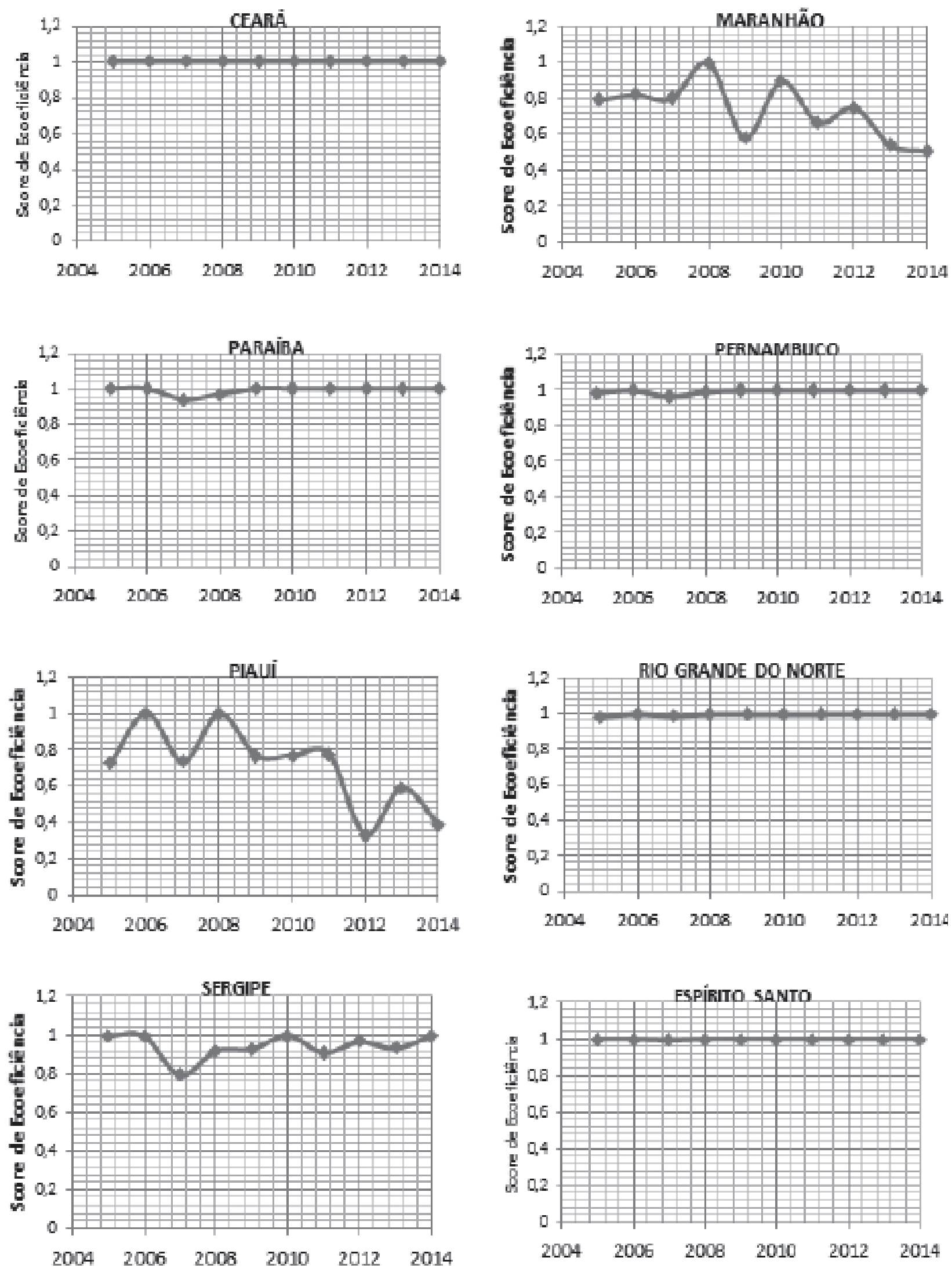

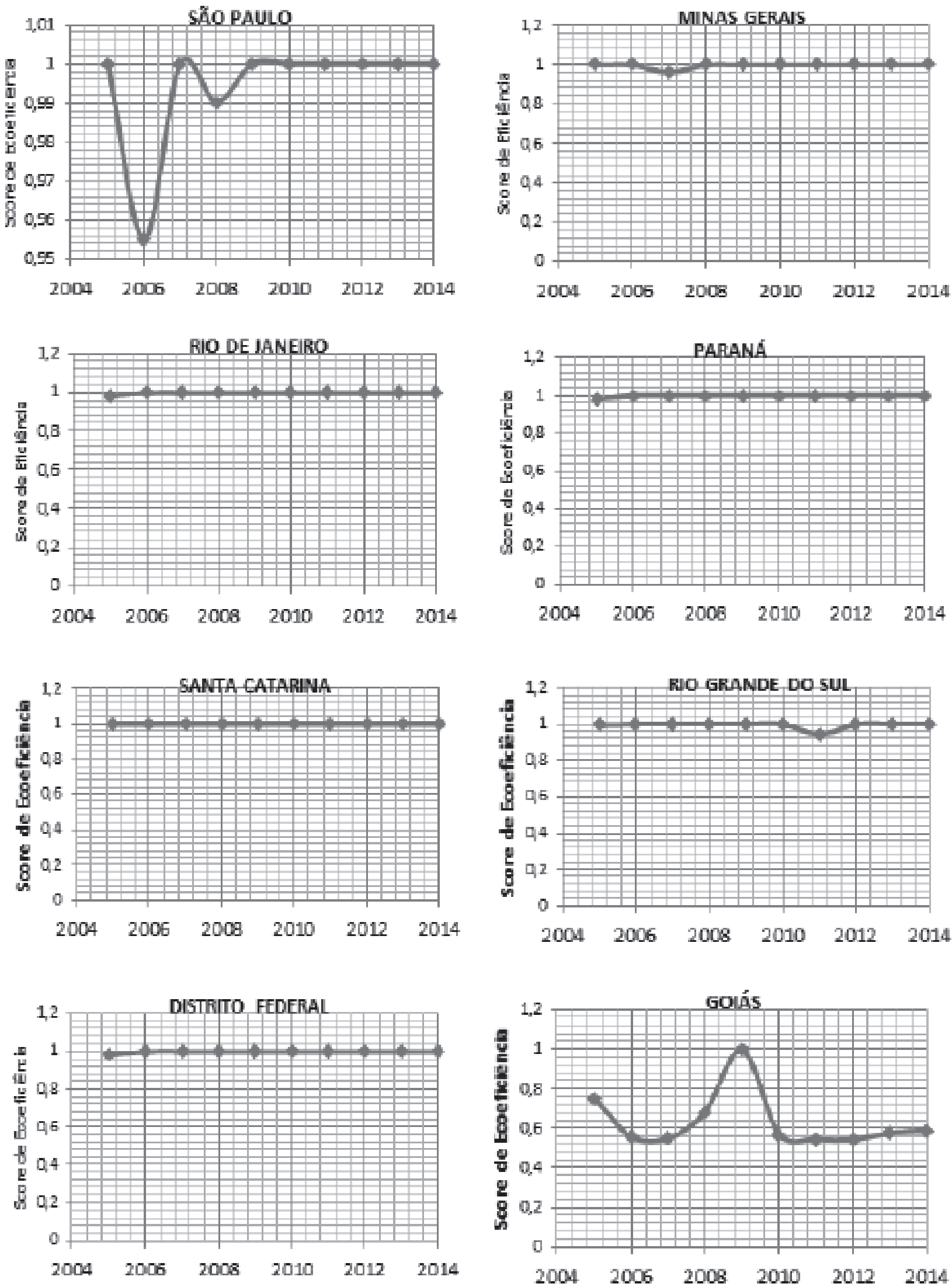


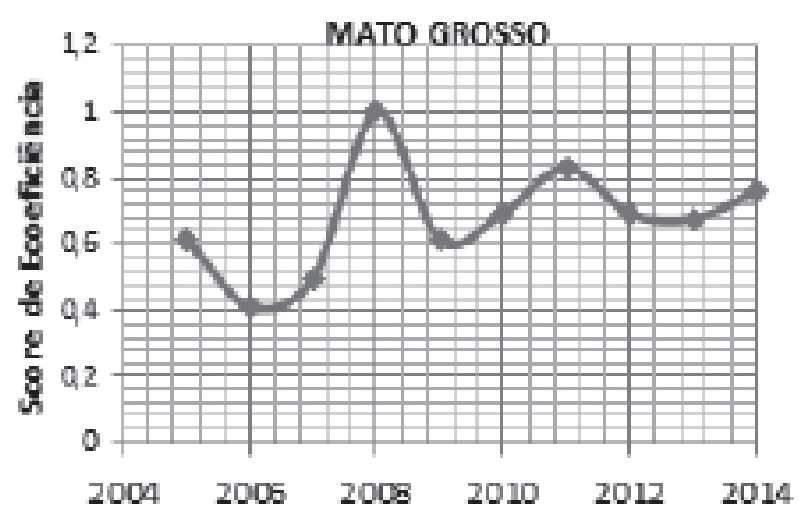

Fonte: Dados da pesquisa (2017).

Os estados que podem ser considerados modelos de ecoeficiência, também denominadas unidades benchmarking, para os demais estados, consistem em: Alagoas, Bahia, Ceará, Paraíba, Pernambuco, Rio Grande do Norte, Espírito Santo, Minas Gerais, Rio de Janeiro, Paraná, Santa Catarina, Rio Grande do Sul e Distrito Federal. O estado de São Paulo, supracitado com números elevados nas estatísticas referentes às variáveis analisadas (inputs e outputs), também apresenta um bom índice de ecoeficiência, porém constante somente a partir de 2009, ou seja, da última década. Em 2006 e 2008, não apresentou total ecoeficiência, o que caracterizou a instabilidade na década passada.

Percebe-se que esses dados vão ao encontro do conceito de ecoeficiência dado pelo WBCSD (2000a), o qual explicita que as organizações ecoeficientes tendem a ter um maior potencial econômico, visto que se utiliza recursos adequadamente, utilizando menos o que precisam pagar e produzindo menos pelo que poderiam ser autuados, como a poluição. A fim de ratificar, destaca-se que todos os estados das regiões Sul e Sudeste (regiões com maiores PIB do Brasil) são ecoeficientes.

De modo genérico, os índices dos estados oscilaram bastante na análise longitudinal, contudo é possível apontar os estados com os menores índices de ecoeficiência no período analisado (2005 a 2014): Acre, Roraima, Rondônia, Tocantins, Piauí e Mato Grosso do Sul.

Os estados mais pobres do País integram também a lista dos menos ecoeficientes - como Roraima (menor PIB no período analisado) e Acre (menor abastecimento de água) -, o que condiz com a preocu-

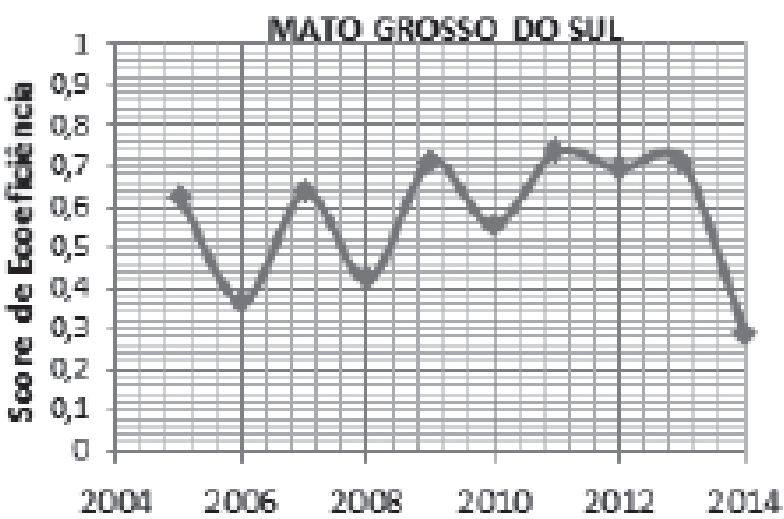

pação exposta por Franklin e Spinler (2011). Para os autores, a atitude ecoeficiente nos modelos de gestão ainda é recente, contudo, já se sabe que reflete em uma importância não só ambiental, mas também de ordem econômica e social. Por isso, ter uma atitude ecoeficente é fundamental e urgente.

Portanto, observa-se a relação direta entre a situação econômica do estado e seu índice de ecoeficiência. Tal afirmação contrapõe o estudo de Pereira, Santa e Andrade (2012), quando concluíram que o conceito de ecoeficiência não abrange $o$ contexto do governo, uma vez que esse conceito visa ao lucro. Contudo, ratifica a opinião de Silva (1998), Monteiro e Nogueira (2006), quando expressam que o meio ambiente, integrante da ordem social, está diretamente associado ao desenvolvimento justo e ao direito humano à qualidade de vida. Para os autores, o desenvolvimento social representa o equilíbrio ambiental, equidade social e crescimento econômico. Complementando, Bai et al. (2018) consideram que produzir mais com menos recursos traduz-se em produzir com eficácia. Logo, a ação ecoeficiente é a direção para a evolução sustentável e para o crescimento econômico justo.

Com o objetivo de reunir os resultados, proporcionando uma melhor compreensão da quantidade de estados e suas respectivas frequências associadas à ecoeficiência ou não durante o período analisado, os scores de ecoeficiência foram classificados através da representação estatística de distribuição de frequência, atribuída pela Frequência Absoluta (FA) e Frequência Relativa (FR) com distribuição regional, conforme segue na Tabela 2: 
Tabela 2 Frequência Absoluta (FA) e Frequência Relativa (FR)

\begin{tabular}{|c|c|c|c|c|c|c|c|}
\hline \multirow{2}{*}{ Regiões } & \multirow{2}{*}{ Estados } & \multicolumn{2}{|c|}{ Ecoeficiência } & \multicolumn{2}{|c|}{ Ineficiência } & \multicolumn{2}{|c|}{ Partic. Regional } \\
\hline & & Freq Abs & Freq Relat & Freq Abs & Freq Relat & Ecoeficiência & Ineficiência \\
\hline \multirow{6}{*}{$\begin{array}{l}\stackrel{\mathscr{V}}{0} \\
\frac{1}{Z}\end{array}$} & Acre & 1 & $0,78 \%$ & 9 & $6,82 \%$ & \multirow{6}{*}{$0,78 \%$} & \multirow{6}{*}{$44,70 \%$} \\
\hline & Amazonas & 0 & $0,00 \%$ & 10 & $7,58 \%$ & & \\
\hline & Rondônia & 0 & $0,00 \%$ & 10 & $7,58 \%$ & & \\
\hline & Roraima & 0 & $0,00 \%$ & 10 & $7,58 \%$ & & \\
\hline & Pará & 0 & $0,00 \%$ & 10 & $7,58 \%$ & & \\
\hline & Tocantins & 0 & $0,00 \%$ & 10 & $7,58 \%$ & & \\
\hline \multirow{9}{*}{$\begin{array}{l}\frac{Q}{\tilde{u}} \\
\frac{0}{0} \\
\frac{0}{Z}\end{array}$} & Alagoas & 8 & $6,20 \%$ & 2 & $1,52 \%$ & \multirow{9}{*}{$42,64 \%$} & \multirow{9}{*}{$26,52 \%$} \\
\hline & Bahia & 8 & $6,20 \%$ & 2 & $1,52 \%$ & & \\
\hline & Ceará & 10 & $7,75 \%$ & 0 & $0,00 \%$ & & \\
\hline & Maranhão & 1 & $0,78 \%$ & 9 & $6,82 \%$ & & \\
\hline & Rio Grande do Norte & 7 & $5,43 \%$ & 3 & $2,27 \%$ & & \\
\hline & Paraíba & 8 & $6,20 \%$ & 2 & $1,52 \%$ & & \\
\hline & Pernambuco & 7 & $5,43 \%$ & 3 & $2,27 \%$ & & \\
\hline & Piauí & 2 & $1,55 \%$ & 8 & $6,06 \%$ & & \\
\hline & Sergipe & 4 & $3,10 \%$ & 6 & $4,55 \%$ & & \\
\hline \multirow{4}{*}{ 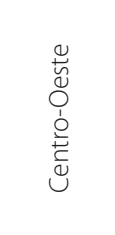 } & Goiás & 1 & $0,78 \%$ & 9 & $6,82 \%$ & \multirow{4}{*}{$8,53 \%$} & \multirow{4}{*}{$21,97 \%$} \\
\hline & Mato Grosso & 1 & $0,78 \%$ & 9 & $6,82 \%$ & & \\
\hline & Mato Grosso do Sul & 0 & $0,00 \%$ & 10 & $7,58 \%$ & & \\
\hline & Dist. Federal & 9 & $6,98 \%$ & 1 & $0,76 \%$ & & \\
\hline \multirow{4}{*}{ 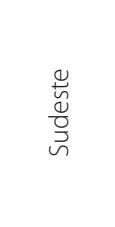 } & Espírito Santo & 9 & $6,98 \%$ & 1 & $0,76 \%$ & \multirow{4}{*}{$27,13 \%$} & \multirow{4}{*}{$3,79 \%$} \\
\hline & Minas Gerais & 9 & $6,98 \%$ & 1 & $0,76 \%$ & & \\
\hline & São Paulo & 8 & $6,20 \%$ & 2 & $1,52 \%$ & & \\
\hline & Rio de Janeiro & 9 & $6,98 \%$ & 1 & $0,76 \%$ & & \\
\hline \multirow{4}{*}{$\bar{\aleph}$} & Paraná & 9 & $6,98 \%$ & 1 & $0,76 \%$ & \multirow{3}{*}{$20,93 \%$} & \multirow{3}{*}{$3,03 \%$} \\
\hline & Rio Grande do Sul & 8 & $6,20 \%$ & 2 & $1,52 \%$ & & \\
\hline & Santa Catarina & 10 & $7,75 \%$ & 1 & $0,76 \%$ & & \\
\hline & Total & 129 & $100 \%$ & 132 & $100 \%$ & $100 \%$ & $100 \%$ \\
\hline
\end{tabular}

Fonte: Elaborado pelos autores (2017).

Com a divisão por regiões apresentada, ressalta-se a distância da ecoeficiência em que se apresentam algumas regiões. Em termos nacionais, o Norte contribui com somente $0,78 \%$ para a ecoeficiência do País, e um índice de $44,70 \%$ de ineficiência. $\mathrm{Na}$ sequência, é apresentada a região Nordeste, a qual, embora apresente o maior índice de ecoeficiência na comparação por regiões $(42,65 \%)$, expressa também o segundo maior índice de ineficiência (26,52\%). O destaque é o estado do Ceará, que apresentou $100 \%$ de ecoeficiência em todo o período analisado. Em contrapartida, Maranhão, Piauí e Sergipe apresentaram baixas frequências de ecoeficiência. No Centro-Oeste, a única unidade federativa que consegue manter a 
frequência de ecoeficiência alta é Distrito Federal, sendo que Goiás, Mato Grosso e Mato Grosso do Sul demonstram frequência quase absoluta de ineficiência. Já as regiões Sul e Sudeste representam os maiores índices de ecoeficiência por estado. Todas as unidades federativas dessas regiões apresentam mais de $6 \%$ de ecoeficiência em comparação nacional, sendo que Santa Catarina destaca-se por demonstrar $100 \%$ de ecoeficiência nos dez anos analisados. Se os resultados das duas regiões forem agrupados, o índice de ecoeficiência $(48,06 \%)$ ultrapassa o da maior região do Brasil (Nordeste), ao mesmo tempo em o índice de ineficiência permanece muito abaixo $(6,82 \%)$ de cada uma das demais regiões.

A ecoeficiência, quando associada ao desenvolvimento sustentável e crescimento econômico, reflete em impactos para os governos estaduais e federal, responsáveis pelo desenvolvimento social justo por meio da utilização e gestão de recursos. Considerando isso, entende-se que a administração pública, em acordo com seus princípios, precisa tomar decisões direcionadas à atitude ecoeficiente, explorando as possibilidades de gestão de recursos e atentando-se para as urgências de cada estado, com o propósito de garantir o bem-estar social e a qualidade de vida adequada para cada cidadão, como impõe a Constituição Federal vigente.

Como ponto integrante à configuração da segunda etapa, foi analisada a relação entre ecoeficiência e o desempenho social, por meio do emprego do método de correlação linear de Pearson "A Correlação de Pearson mensura a associação linear entre duas variáveis métricas" (HAIR et al., 2005, p. 313). A Tabela 3 dispõe dos resultados obtidos ao empregar o referido método.

Tabela 3 Coeficiente de correlação de Pearson

\begin{tabular}{l|c|c} 
& FDH_Output & Gini \\
\hline FDH_Output & 1.000 & \\
\hline Gini & $-0.6029^{*}$ & 1.000 \\
\hline
\end{tabular}

* Significância de 1\%

** Significância de 5\%

Fonte: Dados da pesquisa gerados pelo software STATA 13

Para compreensão dos resultados obtidos na matriz de correlação é importante salientar que quanto maior o coeficiente de correlação, maior será seu nível de associação ou mais forte a sua ligação, e, por conseguinte, maior será a precisão preditiva, descrevendo quão forte é a associação, ao vislumbrar quão próximo os dados seguem uma tendência linear (AGRESTI; FINLAY, 2012)

Como apoio para a análise, o quadro 3 ilustra o grau de associação do coeficiente de correlação, indicando a força de associação, a qual é representada por cores.

Quadro 3 Coeficiente de correlação

\begin{tabular}{c|c}
\hline Variação do coeficiente & Força de Associação \\
\hline $\pm 0,91 \mathrm{a} \pm 1,00$ & Muito forte \\
\hline $\pm 0,71 \mathrm{a} \pm 0,90$ & Alta \\
\hline $\pm 0,41 \mathrm{a} \pm 0,70$ & Moderada \\
\hline $\pm 0,21 \mathrm{a} \pm 0,40$ & Pequena, mas definida \\
\hline $\pm 0,01 \mathrm{a} \pm 0,20$ & Leve, quase imperceptível \\
\hline
\end{tabular}

Fonte: Hair et. al. (2005, p. 312)

Apoiado no coeficiente evidenciado na tabela 3 , os resultados apontam que a variável ecoeficiência (FDH_ Output) apresenta correlação negativa moderada, na ordem de - 0,6029 com a variável de Desempenho Social (Gini). Em outras palavras, a variação da ecoeficiência é associada em aproximadamente - 0,6029 à variação da distribuição de riquezas dos estados brasileiros.

Ao inferir os resultados dispostos, cumpre evidenciar que a lógica do índice de Gini se concentra em uma escala de 0 (inexistência de desigualdade) a 1 (desigualdade máxima), de modo que, quanto mais reduzido é o valor numérico do coeficiente de Gini, menor é o nível de desigualdade da região analisada. Neste aspecto, o valor negativo obtido neste estudo sugere que o índice de Gini tende a diminuir à medida que o score de ecoeficiência aumenta. Foi o que se pode observar tanto na Figura 2 quanto na Tabela 2, as quais atestaram que as regiões e estados brasileiros mais ricos apresentam ecoeficiência, enquanto os mais pobres não são ecoeficientes.

Observa-se, portanto, que o modelo não revelou alta ou muito forte correlação entre as variáveis elencadas, contudo o fato de evidenciar associação moderada negativa remete a novas compreensões a respeito da temática, uma vez que o índice de Gini é 
considerado um parâmetro internacional comumente empregado para mensuração da distribuição de renda.

Nesse sentido, a análise apresentada vai ao encontro do estudo do que afirmam Borges, Monteiro e Nogueira (2006), quando expõem que o desenvolvimento sustentável é baseado no tripé equilíbrio ambiental, equidade social e crescimento econômico, como também ratifica os estudos de John Elkington, quando, na década de 1990, criou a expressão triple bottom line, a qual sugere que o desenvolvimento sustentável deve levar em conta os fatores ambientais, econômicos e sociais.

\section{CONSIDERAÇÕES FINAIS}

O propósito desta pesquisa consistiu na identificação da relação entre ecoeficiência e o desempenho social dos estados brasileiros. O trabalho consistiu em um perfil descritivo, com uma abordagem quantitativa cujo processo ocorreu em dois momentos: para estabelecer os scores de ecoeficiência, na primeira etapa foi empregada a técnica não paramétrica FDH (Free Disposability Hull) com o modelo orientado para insumos; e na sequência foi utilizada a correlação linear de Pearson, com o intuito de analisar o grau de associação entre os constructos investigados.

A partir da aplicação desses métodos, observou-se a relação inversa entre a situação econômica de cada unidade federativa analisada e seu índice de ecoeficiência. Como prova disso, cita-se que todos os estados da região Sul e Sudeste, as quais apresentam os maiores PIB do Brasil, são ecoeficientes, enquanto os estados mais pobres do País, como Roraima (menor PIB no período analisado) e Acre (menor abastecimento de água), integram também a lista dos menos eficientes. Nesse ponto, lembra-se ainda que a correlação entre os scores de ecoeficiência dos estados e suas respectivas distribuições de renda apresentou resultado negativo de aproximadamente - 0,6029, resultado obtido com a aplicação da correlação linear de Pearson. De modo mais profundo, cabe expor que a associação moderada negativa direciona à compreensão da grande importância da ecoeficiência para os estados, já que o Índice de Gini é um indicador utilizado internacionalmente para análise da distribuição de renda.
Ainda que o presente estudo demonstre ineditismo na sua proposta e resultados, é possível compará-lo a pesquisas semelhantes. É o caso do que foi visto em Reyes e Vicente (1998), Silva (1998), Almeida (2002), Monteiro e Nogueira (2006), Van Berkel (2006), e Franklin e Spinler (2011). Para todos esses autores, a atitude ecoeficiente dentro das organizações, incluindo os governos, é fundamental e urgente, uma vez que o meio ambiente está diretamente associado ao desenvolvimento justo e ao direito humano à qualidade de vida. A ação ecoeficiente é, portanto, a direção para a evolução sustentável e para o crescimento econômico justo, resultando assim em um desenvolvimento social equilibrado e eficaz. Em contexto mais recente, Amarante e Tortato (2016) lembram que, ainda que exista uma evidente pluralidade no conceito de ecoeficiência, todas as abordagens direcionam-se para um campo comum, indicando como marco principal, a WBCSD.

A pesquisa aqui realizada e apresentada serve como ponto de partida para análise das gestões de cada unidade federativa exposta, a fim de que reajustem suas ações, quando necessário, visando à atitude ecoeficiente, com o objetivo de usufruir as vantagens da ecoeficiência, como foi apresentado. Por outro lado, as gestões dos estados que já se mostram ecoeficientes podem fazer uso dos dados expostos com o intuito de manter as ações estratégicas que garantem a constância da ecoeficiência. Portanto, espera-se que tais resultados norteiem, quanto ao apelo prático, às políticas públicas e estratégias dos gestores públicos no que tange à eficiência econômica ambiental e a distribuição de renda dos Estados.

Em termos teóricos, ainda que devam ser observadas limitações como a disparidade de dados e falta de informações de alguns estados, este trabalho faz-se útil como o início de outros que possam vir a ser realizados, os quais venham a abordar o tema ecoeficiência e o desempenho social das Unidades Federativas do Brasil.

Por oportuno, a partir da constatação da correlação negativa moderada entre os constructos analisados, cabe sugerir novas investigações sob o prisma do nível de impacto da ecoeficiência no desempenho social, com o emprego de modelos econométricos e de regressão, para continuidade da presente pesquisa, promovendo novas discussões profícuas acerca da temática. 


\section{REFERÊNCIAS}

AGRESTI, A.; FINLAY, B. Métodos estatísticos para as Ciências Sociais: métodos de pesquisa. 4. ed. Porto Alegre: Penso, 2012.

ALCÂNTARA, V. de C; PEREIRA, J. R.; SILVA, E. A. F. Gestão Social e Governança Pública: aproximações e (de) limitações teórico-conceituais. Revista de Ciências da Administração, v. 1, n. 3, p. 11-29, 2015.

ALMEIDA, F. O Bom Negócio da Sustentabilidade. Rio de Janeiro: Nova Fronteira, 2002.

AMARAnTe, J. G. M. C. C.; TORTATO, U. Proeminências da ecoeficiência: uma revisão sistemática das produções internacionais de alto impacto. In: Revista Livre de Sustentabilidade e Empreendedorismo, v. 1, n. 3, p. 3-27, 2016.

ARRETCHE, M. Democracia e redução da desigualdade econômica no Brasil. A inclusão de outsiders. Revista Brasileira de Ciências Sociais, v. 33, n. 96, 2018.

BAI, Y., DENG, X., JIANG, S., ZHANG, Q., WANG, Z. Exploring the relationship between urbanization and urban eco-efficiency: Evidence from prefecture-level cities in China. Journal of Cleaner Production, v. 1 , p. 1487-1496, 2018.

BARBIERI, J. C. Gestão ambiental empresarial: conceitos, modelos e instrumentos. São Paulo: Saraiva, 2004.

BORGES, A.; MONTEIRO, M.; NOGUEIRA, R. Sustentabilidade: o papel da empresa socialmente responsável em uma sociedade sustentável. Rio de Janeiro, 2006.

BECK, U. Sociedade de risco: rumo a uma outra modernidade. Trad. De Sebastião Nascimento. São Paulo: Ed. 34, 2010.

BLEISCHWITZ, R. Cognitive and institutional perspectives of eco-efficiency. Ecological Economics, 46, 2003.
BOOS, T-M. Responsabilidade sócioambiental: estudo de caso do desenvolvimento regional sustentável em Santa Catarina. Monografia apresentada ao Programa de Pós-Graduação em Administração. Universidade Federal do Rio Grande do Sul: Blumenau, 2007.

DARAIO, C; SIMAR, L. Advanced robust and nonparametric methods in efficiency analysis: methodology and applications, Springer Science + Business Media, Inc., New York, 2007.

DEBREU, G. The Coefficient of Resource Utilization, Econometrica, 19, 3, 273-292. 1951.

DEL RÍO, P; MORÁN, M.A.; ALBIÑANA, F.C. Analysing the determinants of environmental technology investments. A panel-data study of Spanish industrial sectors. In: Journal of Cleaner Production, v. 19, pp. 1170-1179, 2011.

DONAIRE, D. Gestão ambiental na empresa. 2. ed. São Paulo: Atlas, 2009.

FRANKLIN, R.; SPINLER, S.S.S. Shared Warehouses - Sharing Risks and Increasing Eco-efficiency. In: International Commerce Review, v. 10, n. 1, 2011.

GÓMEZ, T; GÉMAR, G; MOLINOS-SENANTE, M; SALA-GARRIDO, R; CABALLERO, R. Measuring the eco-efficiency of wastewater treatment plants under data uncertainty. Journal of environmental management, v. 226, p. 484-492, 2018.

GUO, F.; LO, K.; TONG, L. Eco-Efficiency Analysis of Industrial Systems in the Songhua River Basin: A Decomposition Model Approach. Sustainability, v. 8, n. 12, p. 1271, 2016.

HAIR Jr., J. F et al. Fundamentos de métodos de pesquisa em administração. Porto Alegre: Bookman, 2005. 
HINTERBERGER, F., BAMBERGER, K., MANSTEIN, C., SCHEPELMANN, P., SCHNEIDER, F., \& PSANGER-BERG, J. Eco-efficiency of Regions. Sustainable Europe Research. Institute Publishing, Wien, 2000.

HUANG, Y; LI,L; YU,Y. Does urban cluster promote the increase of urban eco-efficiency? Evidence from Chinese cities. Journal of Cleaner Production, V. 197, p. 957-971, 2018.

HUANG, J., YANG, X., CHENG, G., WANG, S., 2014. A comprehensive eco-efficiency model and dynamics of regional eco-efficiency in China. Journal of Cleaner Production. 67 (6), 228e238, 2014.

JABBOUR, C.J.C. Non-linear path ways of corporate environmental management: a survey of ISO 14001-certified companies in Brazil. In: Journal of Cleaner Production, v. 18, 2010.

JABBOUR, C.J.C.; SANTOS, F.C.A.; BARBIERI, J.C. Gestão ambiental empresarial: um levantamento da produção científica brasileira divulgada em periódicos da área de administração entre 1996 e 2005. In: Revista de Administração Contemporânea (RAC), v. 12, n. 3, 2008.

JANNUZZI, P. de M. Considerações sobre o uso, mau uso e abuso dos indicadores sociais na formulação e avaliação de políticas públicas municipais. In: Revista de Administração Pública, v. 36, n. 1, 2002.

KRAJNC, D.; GLAVIC, P. Indicators of sustainable production. In: Clean Techn Environ Policy, v. 5, n. 3, 2003.

LENZA, Pedro. Direto constitucional esquematizado. 15. ed. São Paulo: Saraiva, 2011.

LI, Z., OUYANG, X., DU, K., ZHAO, Y. Does government transparency contribute to improved eco-efficiency performance? An empirical study of 262 cities in China. Energy Policy, 110, 79-89, 2017.
LORENZETTI, D. H.; CRUZ, R. M.; RICIOLI, S. Estratégia empresarial e sustentabilidade: um modelo integrador. In: Revista da Pós-graduação: Administração, Osasco, v.2, n.3, 2008.

MARTÍNEZ ALIER, J. O ecologismo dos pobres: conflitos ambientais e linguagens de valoração. Trad. Maurício Waldman. São Paulo: Contexto, 2007.

MIRZAEI, S., BORZADARAN, G. R. M., AMINI, M., JABBARi, H. A comparative study of the Gini coefficient estimators based on the regression approach. Communications for Statistical Applications and Methods, v. 24, n. 4, p. 339-351, 2017.

MUNCK, L; OlIVEIRA, F. A. C.; BANSI, A. C. Ecoeficiência: uma análise das metodologias de mensuração e seus respectivos indicadores. In: Revista de Gestão Social e Ambiental - RGSA, São Paulo, v. 5, n. 3, p. 183-199, set./dez. 2011.

OGGIONIA, G.; RICCARDIA, R.; TONINELLIB, R. Ecoefficiency of the world cement industry: a data envelopment analysis. Energy Policy, v. 39, n. 5, 2011.

PENA, R. F. A. Coeficiente de Gini. In: Alunos Online - UOL (2017). Disponível em: <http://alunosonline. uol.com.br/geografia/coeficiente-gini.html $>$. Acesso em 20 jan. 2017.

PEREIRA, H. M. K.; SANTA, A. A. W. D.; ANDRADE, B. S. O conceito de ecoeficiência e o papel das políticas públicas na efetivação da gestão ambiental. In: $3^{\circ}$ Congresso Internacional de Tecnologias para o Meio Ambiente. Bento Gonçalves, 2012.

PNUD. Explica transição dos Objetivos do Milênio aos Objetivos de Desenvolvimento Sustentável. Disponível em: https://nacoesunidas.org/pnud-explica-transicao-dos-objetivos-do-milenio-aos-objetivos-de-desenvolvimento-sustentavel/ acesso: 03/01/2018

ROSSETTI, J. P. Introdução à Economia. 20 ed. São Paulo: Atlas, 2007. 
SCHALTEGGER, S., STURM, A 1990.Öologische Rationalität (German/in English: Environmental rationality). Die Unternehmung, 4, 117 - 131.

SCHMIDHEINY, S. Changing course: A global business perspective on development and the environment (Vol. 1). MIT press, 1992.

SILVA, J. A. Direito Ambiental Constitucional. São Paulo: Malheiros, 1998.

ULTSCH, A; LÖTSCH, J. A data science based standardized Gini index as a Lorenz dominance preserving measure of the inequality of distributions. PloS one, v. 12, n. 8, 2017

VAN BERKEL, R. Cleaner production and eco-efficiency. In: MARINOVA, D.; ANNANDALE, D.; PHILLIMORE, J. The International Handbook on Enviromental Technology Management. Edward Elgar, pp. 67-92, 2006.

WBCSD, World Business Council for Sustainable Development. Ecoefficiency: Creating More Value With Less impact. Geneva, Switzerland, 2000a.

Measuring ecoefficiency: a guide to reporting company performance. Geneva, Switzerland, 2000b. 